\title{
Desenvolvimento de material de referência para microbiologia de alimentos contendo estafilococos coagulase positiva em matriz queijo
}

\author{
Development of reference material for the microbiology of foods \\ containing coagulase-positive Staphylococcus in a cheese matrix
}

\begin{abstract}
Autores | Authors
\ Marcelo Luiz Lima BRANDÃO

Instituto Nacional de Controle de Qualidade em Saúde (INCQS)

Departamento de Microbiologia

Av. Brasil, 4365, Manguinhos CEP: 21040-900

Rio de Janeiro/RJ - Brasil e-mail: marcelo.brandao@incqs.fiocruz.br

\section{Juliana de Castro Beltrão da COSTA}

Felipe Miceli de FARIAS Carla de Oliveira ROSAS

Silvia Maria Lopes BRICIO

Instituto Nacional de Controle de Qualidade em Saúde (INCQS)

Departamento de Microbiologia Rio de Janeiro/RJ - Brasil e-mail: juliana.costa@incqs.fiocruz.br micelifmf@gmail.com carla.rosas@incqs.fiocruz.br silvia.bricio@incqs.fiocruz.br

Janaína dos Santos NASCIMENTO

Instituto Federal de Ciência, Educação e Tecnologia do Rio de Janeiro (IFRJ) Departamento de Microbiologia Rio de Janeiro/RJ - Brasil e-mail: janaina.nascimento@ifrj.edu.br

Paola CARDARELLI-LEITE

Instituto Nacional de Controle de Qualidade em Saúde (INCQS)

Departamento de Microbiologia Rio de Janeiro/RJ - Brasil e-mail: paola.cardarell@incqs.fiocruz.br
\end{abstract}

Autor Correspondente / Corresponding Author

Recebido / Received: 14/08/2012 Aprovado / Approved: 29/01/2013 Publicado / Published: mar./2013

\section{Resumo}

O uso de materiais de referência (MR) é uma das principais ferramentas utilizadas para garantia e controle da qualidade de laboratórios de microbiologia de alimentos. No Brasil, a RDC n. ${ }^{\circ}$ 12/01 da Anvisa prevê como um dos parâmetros para a avaliação da qualidade de queijos a enumeração de estafilococos coagulase positiva (ECP). O grande desafio na produção de MR destinados a ensaios microbiológicos é a instabilidade natural dos micro-organismos, o que dificulta o desenvolvimento e a manutenção desses MR. O objetivo deste estudo foi produzir um MR quantitativo destinado ao ensaio de enumeração de ECP em matriz queijo. Uma amostra de queijo ultrafiltrado com contagem de ECP $<10$ UFC/g e número de aeróbios viáveis de 1,22 × $10^{3} \mathrm{UFC} / \mathrm{g}$ foi utilizada como matriz para produção do MR. A matriz foi distribuída em frascos, contaminada com a bactéria alvo em concentração específica e submetida à liofilização. Como crioprotetor, foi utilizada sacarose. O MR produzido foi considerado homogêneo e estável à temperatura $\leq-70{ }^{\circ} \mathrm{C}$ durante todo o período estudado (dez meses). O material apresentou estabilidade a 4, 25, 30 e $35^{\circ} \mathrm{C}$ durante quatro dias; contudo, os resultados indicam que, a $35^{\circ} \mathrm{C}$, ocorre um decréscimo na concentração celular. A $-20^{\circ} \mathrm{C}$, o MR apresentou-se estável durante 48 dias. Conclui-se que o material apresentou todos os requisitos necessários de um MR de qualidade e poderia ser transportado aos laboratórios participantes de um ensaio de proficiência a temperaturas de até $35{ }^{\circ} \mathrm{C}$ por até quatro dias, uma vez que os resultados indicaram a manutenção da concentração celular neste período. Esse foi o primeiro trabalho a descrever uma metodologia de produção de MR contendo ECP em matriz queijo.

Palavras-chave: Material de referência; Queijo; Estafilococos.

\section{Summary}

The use of reference materials (RM) is one of the principal tools used for assurance and quality control in food microbiology laboratories. In Brazil, Anvisa RDC $n^{\circ} 12 / 01$ specifies the enumeration of coagulase-positive staphylococcus (CPS) as one of the parameters for evaluating cheese quality. The main challenge in the production of RM destined for microbiological assays is the natural instability of the microorganisms, which makes it difficult to develop and maintain them. This study aimed to produce a quantitative RM for use in enumeration assays of CPS in cheese matrixes. A sample of an ultra-filtered cheese with a CPS count of $<10 \mathrm{CFU} / \mathrm{g}$ and a total $\mathrm{n}^{\circ}$ of viable aerobes of $1.2 \times 10^{3} \mathrm{CFU} / \mathrm{g}$ was used as the matrix to produce the RM. The matrix was distributed in flasks, contaminated with specific concentrations of the target bacteria and submitted to freeze-drying. Sucrose was used as the cryo-protector. The RM produced was considered homogeneous and stable at $\leq-70^{\circ} \mathrm{C}$ during the entire study period (10 months). The material was shown to be stable at $4,25,30$ and $35^{\circ} \mathrm{C}$ for 4 days, although the results indicated a decrease in cell concentration at $35^{\circ} \mathrm{C}$. At $-20^{\circ} \mathrm{C}$ the RM was stable for 48 days. It was concluded that the material showed all the necessary requirements for a quality RM and could be transported to the laboratories taking part in a proficiency test at up to $35^{\circ} \mathrm{C}$ for up to 4 days, since the results indicated maintenance of the cell concentrations during this period. This is the first study to describe a methodology for producing MR containing CPS in a cheese matrix.

Key words: Reference material; Cheese; Staphylococcus. 


\section{Introdução}

Um material de referência (MR), de acordo com a NBR ISO/GUIA 30 (ABNT, 2000), é um "[...] material ou substância que tem um ou mais valores de propriedades que são suficientemente homogêneos e bem estabelecidos". O uso de MR é amplamente aceito como ferramenta indispensável e confiável para comparação de resultados de análises, sendo um dos pilares para o controle de qualidade metodológico (ABNT, 2000; PHILIPP et al., 2007). Os MR podem ser utilizados nos laboratórios de microbiologia de alimentos como parte do seu programa de garantia da qualidade, no controle interno dos ensaios, na validação de métodos, no treinamento de pessoal e na avaliação da precisão do laboratório (ABDELMASSIH et al., 2011).

Atualmente, existe uma necessidade de MR para microbiologia de alimentos homogêneos, precisos e estáveis (ABDELMASSIH et al., 2011). Além disso, os MR disponíveis podem apresentar desvantagens, como: dificuldade de manipulação ou dissolução, alto valor de incerteza associada, problemas de heterogeneidade e elevados custos de transporte em temperatura de congelamento (PHILIPP et al., 2007).

Os MR destinados a análises microbiológicas na área de alimentos disponibilizados por provedores de ensaios de proficiência (EP), em geral, atendem aos escopos de ensaios qualitativos (presença/ausência) e quantitativos. Os MR quantitativos visam a avaliar a capacidade do laboratório de enumerar o(s) microorganismo(s) alvo(s) de forma precisa e exata (PETERZ e STENERYD, 1993; INCQS, 2012a, b, c).

A problemática no desenvolvimento e na manutenção de MR para EP na área de microbiologia está na sensibilidade das células às variações de temperatura e ao estresse durante o processo de dessecação (IN'T VELD, 1998; PHILIPP et al., 2007). Alterações na concentração celular ou perdas da viabilidade podem ocorrer durante as etapas de produção e estoque (WESSMAN et al., 2011).

Em sua maioria, os relatos encontrados na literatura científica sobre o preparo de MR destinados a ensaios microbiológicos em alimentos são aqueles que utilizam o leite como matriz (IN'T VELD et al., 1999; SCHULTEN et al., 2001; ROSAS et al., 2010; BRANDAO et al., 2011; INCQS, 2012a, b, c). Também existe um relato da produção de MR em matriz carne bovina (VIEIRA et al., 2011) e outros que utilizaram matrizes inertes, como caldo contendo soro e inositol (PETERZ e STENERYD, 1993), e carbonato de cálcio (ABDELMASSIH et al., 2011).

A necessidade de uma dieta adequada e de uma melhor qualidade de vida, e a busca por alimentos mais saudáveis levaram a um aumento no consumo de leite e produtos lácteos, como o queijo. Dentre os diversos tipos de queijo, o tipo Minas Frescal é um produto tipicamente nacional, de tecnologia simples e de larga aceitação no País. Por ser alimento de pronto consumo e indicado para idosos, gestantes e convalescentes, inclusive em dietas hospitalares, a sua inocuidade é de suma importância para que este não venha a causar riscos à saúde do consumidor (VISOTTO et al., 2011). No Brasil, a RDC n. ${ }^{\circ} 12$ de 2001 (BRASIL, 2001), que estabelece o Regulamento Técnico sobre Padrões Microbiológicos para Alimentos, tem como um dos parâmetros da avaliação da qualidade de queijos a quantificação de estafilococos coagulase positiva (ECP).

Até o momento, pelo menos 50 espécies e subespécies de Staphylococcus spp. com potencial de produção da enzima coagulase já foram descritas. Contudo, seis espécies principais compõem o grupo dos ECP, sendo o Staphylococcus aureus subsp. aureus o principal agente causador de surtos de doenças transmitidas por alimentos (BENNETT e LANCETTE, 2001; HENNEKINNE et al., 2010). A intoxicação transmitida por Staphylococcus spp. enterotoxigênicos é provocada pela ingestão de enterotoxinas pré-formadas nos alimentos (HENNEKINNE et al., 2010).

Em razão da carência de métodos relativos à produção de MR em diferentes matrizes alimentícias e da necessidade do uso dos MR para garantia da qualidade e da confiabilidade dos ensaios realizados nos laboratórios de microbiologia de alimentos, o objetivo deste estudo foi desenvolver um MR quantitativo, para enumeração de ECP em matriz queijo, utilizando-se como técnica de preservação a liofilização.

\section{Material e métodos}

\subsection{Seleção e preparo da matriz}

Uma amostra de queijo Minas produzido pelo processo de ultrafiltração foi analisada para verificação do nível de contaminação por ECP, segundo Bennett e Lancette (2001), e da carga microbiana total de aeróbios viáveis presente na matriz, segundo Maturin e Peeler (2001).

A matriz de queijo foi distribuída, em condições assépticas, em frascos de vidro estéreis com capacidade de $10 \mathrm{~mL}$ ( $2 \mathrm{~g} / \mathrm{frasco})$ até um total de 216 frascos. Rolhas de borracha estéreis para liofilização foram posicionadas nos frascos. Os frascos foram congelados em freezer à temperatura $\leq-70{ }^{\circ} \mathrm{C}$ (Thermo, EUA) por 24 horas $\mathrm{e}$ submetidos a um ciclo de liofilização por 24 horas, em aparelho liofilizador K105 (Liotop, BRASIL).

\subsection{Produção do material de referência}

A metodologia de produção do MR contendo ECP em matriz queijo (MR STA01) desenvolvida neste trabalho 
teve como base o estudo descrito por Rosas et al. (2010). Em adição, foi utilizada a sacarose como crioprotetor para produção do MR (BRANDAO et al., 2011; WESSMAN et al., 2011).

Uma cepa de S. aureus subsp. aureus da coleção de micro-organismos do Setor de Alimentos/INCQS, isolada a partir de uma amostra de queijo tipo "ricota" e identificada pelo Sistema VITEK 2 V. 04.02 (BioMerieux), foi utilizada neste estudo. A cepa foi cultivada em caldo infusão cérebro-coração (Merck, ALEMANHA) a $35^{\circ} \mathrm{C}$ por 24 horas. A cultura foi centrifugada a 10.000 rpm por 10 minutos (Eppendorf, EUA) e o sedimento foi ressuspenso em solução salina peptonada (SSP) a 0,1\%. A concentração de células foi ajustada em aparelho fotocolorímetro (Libra S2, Biochrom, INGLATERRA) em 520 nm até uma transmitância de $2 \%\left(\cong 2,6 \times 10^{9}\right.$ células $\left./ \mathrm{mL}\right)$ e diluída em SSP a 0,1\% contendo $100 \mathrm{mM}$ de sacarose, até atingir uma concentração alvo de 2,6 × $10^{4}$ células/ $\mathrm{mL}$. Esta solução foi homogeneizada e volumes de $0,5 \mathrm{~mL}$ da suspensão foram utilizados para contaminação dos frascos contendo a matriz de queijo pré-liofilizada (item 2.1). Os frascos foram congelados e submetidos novamente a um ciclo de liofilização por 24 horas.

A partir da solução utilizada para contaminação dos frascos, foi realizada a quantificação do número de células em ágar tripticaseína de soja (TSA) (Difco, EUA), incubado a $35^{\circ} \mathrm{C}$ por 48 horas. Essa quantificação foi realizada no momento da contaminação do primeiro e do último frasco, com objetivo de verificar a variação da concentração celular durante o tempo necessário para o preparo do lote.

\subsection{Controle da qualidade do material de referência}

O candidato a MR produzido foi submetido aos ensaios de controle para verificar se este atendia aos requisitos necessários de um MR. A inspeção visual e a verificação de vácuo foram incluídas com a intenção de avaliar a qualidade final do MR liofilizado.

\subsubsection{Inspeção visual e verificação de vácuo}

Após a liofilização, os frascos foram inspecionados visualmente para verificação da presença de possíveis defeitos (aspecto estranho, presença de liquefação ou caramelização das amostras). Posteriormente, foi realizada a verificação do vácuo conforme descrito por Rosas et al. (2010). Os frascos que apresentaram algum defeito ou não apresentaram vácuo foram descartados, e os demais foram lacrados com tampa metálica, identificados e estocados em freezer à temperatura $\leq$ $-70{ }^{\circ} \mathrm{C}$.

\subsubsection{Estudo da homogeneidade}

Dez frascos do lote, selecionados aleatoriamente utilizando-se a ferramenta de números aleatórios do programa do Microsoft Office Exce| ${ }^{\circledast}$ 2010, foram enumerados, em duplicata, sob condições de repetitividade, segundo Bennett e Lancette (2001).

Os frascos selecionados foram reconstituídos com $2 \mathrm{~mL}$ de SSP a 0,1\% e mantidos em repouso durante 15 minutos. Após este período, a matriz foi retirada do frasco e transferida para um saco plástico estéril com filtro (Nasco, EUA), seguido da adição de $16 \mathrm{~mL}$ de SSP a 0,1\% para atingir a proporção 1:10. O saco foi homogeneizado em aparelho Stomacher ${ }^{\circledast}$ (Seward Fisher Scientific, CANADÁ) durante 1 minuto. Alíquotas de 0,5 $\mathrm{mL}$ foram semeadas, em duplicata, em superfície de ágar Baird Parker (Difco, EUA) e as placas incubadas a $35{ }^{\circ} \mathrm{C}$ por 48 horas. Após este período, foi realizada a contagem das colônias características (negras com halo de clarificação).

A homogeneidade foi avaliada segundo o Protocolo Internacional Harmonizado (THOMPSON et al., 2006), atribuindo-se um desvio padrão alvo $\left(\sigma_{p}\right)$ de $0,25 \log _{10}$ UFC/g da concentração celular (INCQS, 2012a, b, c). Primeiramente, as contagens das placas foram convertidas em $\log _{10}$. Em seguida, aplicou-se o teste de Cochran e realizou-se a análise de variância (Anova), utilizando-se o programa Microsoft Office Exce ${ }^{\circledR}$ 2010. A avaliação da homogeneidade foi realizada comparando-se o valor da variância entre as amostras $\left(S^{2}{ }_{\mathrm{am}}\right)$ e o valor crítico da homogeneidade (c), em que o MR é considerado homogêneo quando $\mathrm{S}^{2}{ }_{\mathrm{am}}<\mathrm{C}$.

\subsubsection{Estudo da estabilidade}

O estudo da estabilidade foi realizado em longa e curta duração. O teste em longa duração foi realizado na temperatura de referência $\left(\leq-70^{\circ} \mathrm{C}\right)$. A estabilidade em curta duração foi avaliada em temperaturas que simulam o transporte do MR aos laboratórios nas temperaturas de $4,25,30$ e $35^{\circ} \mathrm{C}$, e na temperatura de estoque nos laboratórios, após o recebimento do $\operatorname{MR}\left(-20^{\circ} \mathrm{C}\right)$.

$\mathrm{O}$ estudo em longo prazo foi realizado segundo o modelo clássico (ISO, 2006) durante o período de dez meses. Foram realizadas sete análises em intervalos de tempo determinados, sendo que, em cada análise, realizou-se a enumeração de seis frascos, selecionados aleatoriamente, utilizando-se a técnica descrita no estudo da homogeneidade.

O estudo em curta duração nas temperaturas de 4 , 25,30 e $35^{\circ} \mathrm{C}$ foi realizado utilizando-se o modelo isócrono (LAMBERTY et al., 1998), que se baseia no estoque dos frascos em diferentes períodos de tempo, com a realização das análises sob condições de repetitividade. Oito frascos do lote estocados à temperatura $\leq-70{ }^{\circ} \mathrm{C}$ foram selecionados aleatoriamente e acondicionados em quatro embalagens (dois por embalagem) próprias para transporte de material biológico (Concepta, BRASIL). A cada dia, estas embalagens foram estocadas nas 
temperaturas de $4,25,30$ e $35^{\circ} \mathrm{C}$, até um total de quatro dias. Após o quarto dia de incubação, os 16 frascos utilizados mais dois frascos estocados a $\leq-70{ }^{\circ} \mathrm{C}$ (dia zero) foram enumerados conforme a técnica descrita no estudo da homogeneidade.

O estudo em curta duração na temperatura de $-20{ }^{\circ} \mathrm{C}$ foi realizado utilizando-se o modelo clássico (ISO, 2006). Este estudo visou a avaliar a estabilidade do MR durante o período em que estaria estocado no laboratório participante, na temperatura de $-20^{\circ} \mathrm{C}$, simulando o prazo de 48 dias de estocagem. Quatorze frascos do lote produzido, selecionados aleatoriamente, foram acondicionados a $-20{ }^{\circ} \mathrm{C}$. Neste mesmo dia, foi realizada a enumeração de estafilococos em dois frascos estocados a $\leq-70{ }^{\circ} \mathrm{C}$ (dia zero). A cada sete dias, dois frascos foram enumerados conforme a técnica descrita no estudo da homogeneidade.

A avaliação da estabilidade do MR foi realizada pela análise de resíduos da regressão em conjunto com a Anova, utilizando-se o programa Microsoft Office Excel $^{\circledR}$ 2010.

\section{Resultados e discussão}

A amostra de queijo selecionada apresentou contagem de ECP $<10 \mathrm{UFC/g}$, sendo assim considerada uma matriz satisfatória para produção do MR. O número total de viáveis aeróbios encontrado foi de 1,2 $\times 10^{3}$ UFC/g. Esta quantificação foi realizada com o objetivo de determinar a carga microbiana presente na amostra.

A concentração celular da suspensão utilizada na contaminação dos frascos se apresentou dentro da mesma faixa logarítmica, contendo 4,134 e 4,141 $\log _{10}$ UFC/mL no início e no término da produção, respectivamente. Os resultados indicam que o tempo total para contaminação dos frascos foi suficiente para estabilização da concentração bacteriana.

$\mathrm{Na}$ inspeção visual dos frascos após a liofilização, foi verificado que o material apresentou coloração branca com ausência de brilho. Nenhuma amostra apresentou colapso ou caramelização.

Em 36 (16,7\%) frascos do lote, não foi detectado vácuo. Este resultado foi similar aos obtidos por outros autores que utilizaram o processo de liofilização no preparo de MR e também obtiveram ausência de vácuo em até $20 \%$ dos lotes produzidos (ROSAS et al., 2010; VIEIRA et al., 2011).
No estudo de homogeneidade, o lote apresentou os resultados de: $\mathrm{C}=0,017$ e $\mathrm{S}^{2}$ am $=0,0064$, sendo assim considerado homogêneo (THOMPSON et al., 2006). O $\sigma_{p}$ de 0,25 atribuído para avaliação deste MR foi baseado no valor adotado pelos provedores de EP, mas, para atender ao critério do Protocolo Internacional harmonizado, o MR produzido seria considerado homogêneo com um $\sigma_{p}$ de até 0,03 .

Outros autores já produziram MR homogêneos utilizando o processo de liofilização. Rosas et al. (2010) produziram dois lotes de MR contendo Salmonella em leite que foram homogêneos com valores de $\sigma_{p}$ de 0,10 e 0,27 . Em três rodadas de EP, lotes contendo Escherichia coli, bactérias mesófilas e Bacillus cereus em leite foram homogêneos com valor de $\sigma_{p}$ de 0,25 (INCQS, 2012a, b, c). Diversamente, Vieira et al. (2011) obtiveram MR homogêneos contendo Salmonella em matriz carne bovina crua; no entanto, ao utilizarem carne cozida e enlatada como matriz, relataram insuficiência de homogeneidade. Com a utilização de outras técnicas de produção, Abdelmassih et al. (2011) produziram dois lotes de MR contendo um esporo de B. cereus e outro esporo de Clostridium perfringens, adsorvidos em precipitados de carbonato de cálcio, que se apresentaram homogêneos. Em pesquisas que utilizaram a técnica de spray-dryer, a comparação dos resultados obtidos foi dificultada, uma vez que os autores utilizaram outro teste estatístico na avaliação da homogeneidade (IN'T VELD et al., 1999; SCHULTEN et al., 2001).

A média das contagens do teste de homogeneidade foi de 3,159 $\log _{10} \mathrm{UFC} / \mathrm{g}$, demonstrando que o lote teve uma perda de $0,376 \log _{10}(10,64 \%)$ de concentração após o processo de liofilização. A sensibilidade aos procedimentos de congelamento e liofilização varia de acordo com a espécie bacteriana e a cepa (PETERZ e STENERYD, 1993). O conhecimento da concentração microbiana, após o processo de liofilização, é importante para que o laboratório produtor considere esse fator no momento do planejamento experimental de preparo do MR, para obtenção da concentração final alvo.

No estudo de estabilidade, a análise estatística de regressão demonstrou que o MR foi considerado estável em todas as temperaturas durante os períodos estudados, pois o intervalo de confiança a 95\% abrange o valor zero (ISO, 2006), conforme visualizado na Tabela 1.

Tabela 1. Análise de regressão do estudo de estabilidade.

\begin{tabular}{lcccccc}
\multicolumn{1}{c}{ Temperatura $\left({ }^{\circ} \mathbf{C}\right)$} & $\leq-\mathbf{7 0}$ & $\mathbf{- 2 0}$ & $\mathbf{4}$ & $\mathbf{2 5}$ & $\mathbf{3 0}$ & $\mathbf{3 5}$ \\
Coeficiente Angular & 0,00045 & 0,00075 & $-0,043$ & $-0,013$ & $-0,0078$ & $-0,24$ \\
Limite Inferior (95\%) & $-0,00053$ & $-0,0069$ & $-0,15$ & $-0,23$ & $-0,094$ & $-0,53$ \\
Limite Superior (95\%) & 0,0014 & 0,0084 & 0,062 & 0,21 & 0,079 & 0,050 \\
Resultado & Estável & Estável & Estável & Estável & Estável & Estável \\
\hline
\end{tabular}


Outros autores também obtiveram resultados satisfatórios na produção de MR estáveis à temperatura $\leq-70{ }^{\circ} \mathrm{C}$, durante todo o período estudado, tendo o leite como matriz e a liofilização (BRANDAO et al., 2011; INCQS, 2012a, b, c) ou spray-dryer (SCHULTEN et al., 2001), como técnica de preservação.

No estudo de estabilidade nas temperaturas de transporte, o maior valor em módulo do coeficiente angular obtido foi na temperatura de $35^{\circ} \mathrm{C}$, demonstrando assim uma variação maior da concentração de células ao longo do tempo (Tabela 1). Essa variação pode ser mais bem visualizada na Figura 1, que apresenta o gráfico da estabilidade em curta duração.

Estes resultados foram similares aos obtidos nas três rodadas de EP realizadas pelo INCQS, em que os MR utilizados apresentaram estabilidade a 4,25 e $35^{\circ} \mathrm{C}$, durante os quatro dias de estudo (INCQS, 2012a, b, c). Apesar de o cálculo estatístico preconizado pela ISO Guide 35 (ISO, 2006) ter considerado o lote estável a 35 ${ }^{\circ} \mathrm{C}$, na Figura 1 é possível observar uma clara tendência no sentido decrescente do número de células ao longo dos dias, indicando que, caso este MR fosse mantido nestas condições por mais tempo, a concentração celular poderia ser comprometida. Esses resultados foram semelhantes aos relatados por Vieira et al. (2011), que conseguiram produzir dois lotes de MR contendo Salmonella em carne bovina estáveis durante quatro dias nas temperaturas de $-20,4$ e $25^{\circ} \mathrm{C}$, porém instáveis a 35 ${ }^{\circ} \mathrm{C}$. Rosas et al. (2010), ao estudarem a estabilidade de um MR contendo Salmonella em matriz leite durante 7 dias, obtiveram estabilidade a $4{ }^{\circ} \mathrm{C}$, mas observaram falta de estabilidade a 25 e $37^{\circ} \mathrm{C}$. Estes autores relataram que a perda expressiva na concentração bacteriana já se inicia no segundo dia de estoque a $37^{\circ} \mathrm{C}$, com subsequentes reduções ao longo dos dias, o que também foi constatado no lote produzido neste estudo.

O MR STA01 poderia ser transportado aos laboratórios participantes de um EP a uma temperatura de até $35^{\circ} \mathrm{C}$ em um período máximo de quatro dias, uma vez

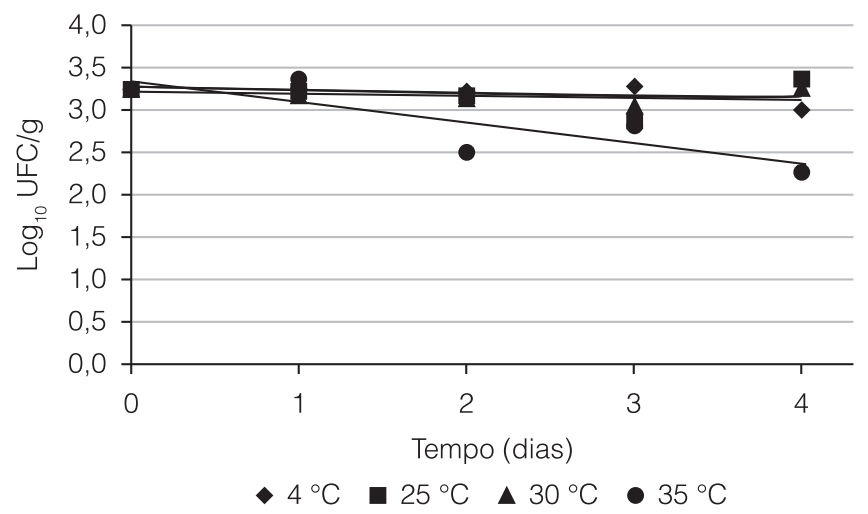

Figura 1. Gráfico de regressão linear das médias de concentração de células, durante a simulação de transporte nas temperaturas de $4,25,30$ e $35^{\circ} \mathrm{C}$ por 4 dias. que os resultados estatísticos indicaram a manutenção da concentração de células do MR neste período. No entanto, durante o envio do MR, seria importante o monitoramento da temperatura ao longo do transporte com o uso de registradores, de forma a garantir que a referida faixa de temperatura e o prazo de envio não sejam excedidos.

Os dados da literatura demonstram que os MR produzidos pela técnica de spray dryer são estáveis por longos períodos a $-20{ }^{\circ} \mathrm{C}$ (IN'T VELD et al., 1999; PHILIPP et al., 2007). No caso dos MR produzidos pelo processo de liofilização, Rosas et al. (2010) observaram que o estoque, por longos períodos a $-20^{\circ} \mathrm{C}$, pode comprometer a estabilidade dos MR. Estes autores produziram dois lotes de MR contendo Salmonella em leite estáveis por três meses, mas com tendência de decréscimo da concentração celular ao longo do tempo, sendo que, após um ano, esses MR não se encontravam mais estáveis. O MR STA01 apresentou estabilidade a $-20{ }^{\circ} \mathrm{C}$ durante 48 dias com baixo valor do coeficiente angular, tendo assim a perspectiva de ser estável nesta condição por um período muito maior. Este resultado pode estar associado ao uso da sacarose como crioprotetor, o que pode ter proporcionado uma maior estabilidade dos micro-organismos na matriz.

A obtenção de MR estáveis por períodos mais longos a temperaturas mais elevadas é importante, pois nem todos os laboratórios possuem equipamentos para armazenar MR à temperatura $\leq-70^{\circ} \mathrm{C}$. Deste modo, os laboratórios que adquirissem os MR poderiam estocá-los em equipamentos mais usuais, como freezer comum, e utilizá-los em um prazo de validade maior.

\section{Conclusões}

Conclui-se que o material apresentou todos os requisitos necessários de um MR de qualidade e poderia ser transportado aos laboratórios participantes de um EP a temperaturas de até $35^{\circ} \mathrm{C}$ por até quatro dias, uma vez que os resultados indicaram a manutenção da concentração celular neste período. Este foi o primeiro trabalho a descrever uma metodologia de produção de MR contendo ECP em matriz queijo.

\section{Agradecimentos}

Ao Programa de Pós-graduação em Ciência e Tecnologia de Alimentos do IFRJ, pela realização do Curso de Mestrado de Marcelo Brandão. À Fiocruz, pela concessão de Bolsa Inovatec à Juliana Costa, e ao CNPQ, pela concessão de Bolsa PIBIC-EM a Felipe Miceli.

\section{Referências}

ABDELMASSIH, M.; PLANCHON, V.; ANCEAU, C.; MAHILLON, $J$. Development and validation of stable reference materials 
Desenvolvimento de material de referência para microbiologia de alimentos contendo estafilococos coagulase positiva em matriz queijo

BRANDÃO, M. L. L. et al.

for food microbiology using Bacillus cereus and Clostridium perfringens spores. Journal of Applied Microbiology, Oxford, v. 110, n. 6, p. 1524-1530, 2011. PMid:21435123. http://dx.doi. org/10.1111/j.1365-2672.2011.05007.x

ASSOCIAÇÃO BRASILEIRA DE NORMAS TÉCNICAS - ABNT. NBR ISO/GUIA 30: Termos e Definições Relacionados com Materiais de Referência. Rio de Janeiro: ABNT, 2000. 6 p.

BENNETT, R. W.; LANCETTE, G. A. Staphylococcus aureus. In: FOOD AND DRUG ADMINISTRATION - FDA. Bacteriological Analytical Manual Online. 8th ed. rev. A 1998. Silver Spring: FDA, jan. 2001. cap. 12.

BRANDAO, M. L. L.; BRICIO, S. M. L.; ROSAS, C. O.; COSTA, J. C. B.; VIEIRA, L. R.; MEDEIROS, V. M.; NASCIMENTO, J. S. Produção de Material de Referência para Contagem de Estafilococos Coagulase Positiva em Matriz Leite em Pó. In: CONGRESSO BRASILEIRO DE MICROBIOLOGIA, 26., 2011, Foz do Iguaçu. Anais... São Paulo: SBM, 2011.

BRASIL. Ministério da Saúde. Agência Nacional de Vigilância Sanitária. Resolução RDC n 12, de 02 de janeiro de 2001. Regulamento Técnico sobre Padrões Microbiológicos para Alimentos. Diário Oficial da República Federativa do Brasil, Brasília, DF, 10 jan. 2001. Seção 1, p. 45.

HENNEKINNE, J. A.; OSTYN, A.; GUILLIER, F.; HERBIN, S.; PRUFER, A. L.; DRAGACCI, S. How should staphylococcal food poisoning outbreaks be characterized?. Toxinis, Postfach, v. 1, n. 8, p. 2106-2116, 2010.

IN'T VELD, P. H. The use of reference materials in quality assurance programmes in food microbiology laboratories. International Journal of Food Microbiology, Amsterdan, v. 45, n. 1, p. 35-41, 1998.

IN'T VELD, P. H.; HAVELAAR, A. H.; VAN STRIJP-LOCKEFEER, N. G. W. M. The certification of a reference material for the evaluation of methods for the enumeration of Bacillus cereus. Journal of Applied Microbiology, Oxford, v. 86, n. 2, p. 266-274, 1999. http://dx.doi.org/10.1046/j.1365-2672.1999.00661.x

INSTITUTO NACIONAL DE CONTROLE DE QUALIDADE EM SAÚDE - INCQS. Ensaio de Proficiência em Produtos Sujeitos ao Regime de Vigilância Sanitária. Ensaio de Proficiência em Microbiologia de Alimentos $2^{a}$ Rodada Enumeração de Coliformes Termotolerantes Matriz Leite em Pó Rodada EP MIB02/11. Relatório final do Ensaio de Proficiência em Microbiologia de Alimentos $2^{a}$ Rodada - MIB02/11. Rio de Janeiro: INCQS, Fiocruz, 2012a. 29 p.

INSTITUTO NACIONAL DE CONTROLE DE QUALIDADE EM SAÚDE - INCQS. Ensaio de Proficiência em Produtos Sujeitos ao Regime de Vigilância Sanitária. Ensaio de Proficiência em Microbiologia de Alimentos $3^{\text {a }}$ Rodada Contagem de Bactérias Mesófilas Matriz Leite em Pó Rodada EP MIB03/11.

Relatório final do Ensaio de Proficiência em Microbiologia de Alimentos $3^{\text {a }}$ Rodada - MIB03/11. Rio de Janeiro: INCQS, Fiocruz, 2012b. 22 p.

INSTITUTO NACIONAL DE CONTROLE DE QUALIDADE EM SAÚDE - INCQS. Ensaio de Proficiência em Produtos Sujeitos ao Regime de Vigilância Sanitária. Ensaio de Proficiência em Microbiologia de Alimentos $4^{\mathrm{a}}$ Rodada Contagem de Bacillus cereus Matriz Leite em Pó Rodada EP MIB04/11. Relatório final do Ensaio de Proficiência em Microbiologia de Alimentos $4^{\mathrm{a}}$ Rodada - MIB04/11. Rio de Janeiro: INCQS, Fiocruz, 2012c. 22 p.

I NTERNATIONAL ORGANIZATION FOR STANDARDIZATION - ISO. ISO GUIDE 35: Reference MaterialsGeneral and Statistical Principles for Certification. Geneva: ISO, 2006. 62 p.

LAMBERTY, A.; SCHIMMEL, H.; PAUWELS, J. The study of the stability of reference materials by isochronous measurements. Fresenius Journal of Analytical Chemistry, Berlin, v. 360, n. 3-4, p. 359-361, 1998. http://dx.doi.org/10.1007/s002160050711

MATURIN, L.; PEELER, J. T. Aerobic plate count. In: FOOD AND DRUG ADMINISTRATION - FDA. Bacteriological Analytical Manual Online. 8th ed. rev. A 1998. Silver Spring: FDA, jan. 2001. cap. 3.

PETERZ, M.; STENERYD, A. C. Freeze-dried mixed cultures as reference samples in quantitative and qualitative microbiological examinations of food. Journal of Applied Bacteriology, Oxford, v. 74, n. 2, p. 143-148, 1993. http://dx.doi. org/10.1111/j.1365-2672.1993.tb03007.x

PHILIPP, W. J.; IWAARDEN, P. V.; SCHIMMEL, H.; MEEUS, N.; KOLLMORGEN, N. Development of reference materials for microbiological analysis. Accreditation and Quality Assurance, New York, v. 12, n. 3-4, p. 134-138, 2007. http:// dx.doi.org/10.1007/s00769-006-0244-3

ROSAS, C. O.; BRANDAO, M. L. L.; BRICIO, S. M. L.; MEDEIROS, V. M.; BERNARDO, S. P. C.; DE LA CRUZ, M. H. C.; CARDARELLILEITE, P. Desenvolvimento de material de referência para ensaio de proficiência em microbiologia de alimentos. Revista do Instituto Adolfo Lutz, São Paulo, v. 69, n. 1, p. 15-22, 2010.

SCHULTEN, S. M.; IN'T VELD, P. H.; GHAMESHLOU, Z.; SCHIMMEL, H.; LINSINGER, T. The Certification of the Number of Colony Forming Particles of Salmonella typhimurium and Number Fraction of Negative Capsules from Artificially Contaminated Milk Power: CRM 507R. Belgium: European Commission, 2001. 74 p.

THOMPSON, M.; ELLISON, S. L. R.; WOOD, R. International harmonized protocol for proficiency testing of (chemical) analytical chemistry laboratories. Pure and Applied Chemistry, Oxford, v. 78, n. 1, p. 145-196, 2006. http://dx.doi.org/10.1351/ pac200678010145

VIEIRA, L. R.; ROSAS, C. O.; BRANDAO, M. L. L.; MEDEIROS, V. M.; COSTA, J. C. B.; BRICIO, S. M. L. Desenvolvimento de 
Desenvolvimento de material de referência para microbiologia de alimentos contendo estafilococos coagulase positiva em matriz queijo

BRANDÃO, M. L. L. et al.

Metodologia para a Produção de Material de Referência em Matriz de Carne Bovina para Detecção de Salmonella spp. In: ENCONTRO NACIONAL DE ANALISTAS DE ALIMENTOS E CONGRESSO LATINO AMERICANO DE ANALISTAS DE ALIMENTOS, 17., 2011, Cuiabá. Anais... São Paulo: SBAAL, 2011.

VISOTTO, R. G.; OLIVEIRA, M. A.; PRADO, S. P. T.; BERGAMINI, A. M. M. Queijo Minas Frescal: perfil higiênico-sanitário e avaliação da rotulagem. Revista do Instituto Adolfo Lutz, São Paulo, v. 70, n. 1, p. 8-15, 2011.

WESSMAN, P.; MAHLIN, D.; AKHTAR, S.; RUBINO, S.; LEIFER, K.; KESSLER, V.; HAKANSSON, S. Impact of matrix properties on the survival of freeze-dried bacteria. Journal of the Science of Food and Agriculture, London, v. 91, n. 14, p. 2518-2528, 2011. PMid:21445855. http://dx.doi.org/10.1002/jsfa.4343 